\title{
Polysaccharides of Scrophularia ningpoensis Hemsl.: Extraction, Antioxidant, and Anti-Inflammatory Evaluation
}

\author{
Jian'an Wang $\mathbb{D}^{1},{ }^{1}$ Lufen Huang $\mathbb{D}^{1},{ }^{1}$ Qiang Ren $\mathbb{D}^{1},{ }^{1}$ Yanjun Wang $\mathbb{D}^{1,2}$,irun Zhou ${ }^{1}{ }^{1}$

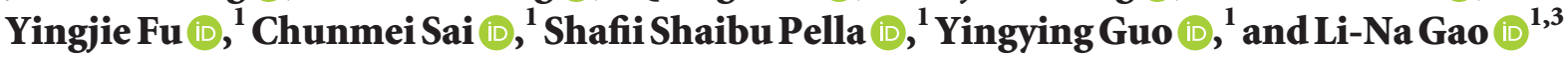 \\ ${ }^{1}$ School of Pharmacy, Jining Medical University, Rizhao, Shandong 276826, China \\ ${ }^{2}$ Maternal and Child Health Care Family Planning Service Center, Ju Xian, Shandong 276500, China \\ ${ }^{3}$ Townsend Family Laboratories, Department of Psychiatry, The University of British Columbia, 2255 Wesbrook Mall, \\ Vancouver BC V6T 1Z3, Canada \\ Correspondence should be addressed to Li-Na Gao; linagao228@126.com
}

Received 30 August 2020; Revised 23 October 2020; Accepted 5 December 2020; Published 15 December 2020

Academic Editor: Jianping Chen

Copyright (c) 2020 Jian'an Wang et al. This is an open access article distributed under the Creative Commons Attribution License, which permits unrestricted use, distribution, and reproduction in any medium, provided the original work is properly cited.

\begin{abstract}
The roots of Scrophularia ningpoensis Hemsl. are a famous traditional Chinese medicinal herb and are also used as health food. However, information about polysaccharides from S. ningpoensis (SNPS) is very limited. We applied the ultrasonic-assisted extraction (UAE) process to extract SNPS. The UAE conditions were optimized using single-factor experiments and response surface analysis. Under the optimized conditions of ultrasonic power of $550 \mathrm{~W}$, extraction time of 26 min, and extraction temperature at $50^{\circ} \mathrm{C}$, the highest yield of $13.47 \% \pm 1.63 \%$ was obtained, which was in accordance with the predicted value of $13.71 \%$. In comparison with traditional hot water extraction, the optimized UAE method significantly increased the extraction yield with lower extraction temperature and shorter extraction time. Furthermore, the in vitro antioxidant evaluation showed that $\mathrm{EC}_{50}$ values of SNPS were $2.43 \pm 0.21,4.40 \pm 0.35$, and $0.56 \pm 0.062 \mathrm{mg} / \mathrm{mL}$ for 2,2-diphenyl-1-picrylhydrazyl radical (DPPH) radical, hydroxyl free radical, and 2,2'-azinobis (3-ethylbenzothiazoline-6-sulfonic acid) (ABTS) radical scavenging assay, respectively. The anti-inflammatory potential of SNPS was detected in lipopolysaccharide (LPS) induced ICR mice. Real-time reverse transcription-polymerase chain reaction and enzyme-linked immunosorbent assay showed that SNPS significantly improved LPS-stimulated inflammatory response by decreasing mRNA and protein expression of interleukin (IL)- 6 and tumour necrosis factor (TNF)- $\alpha$ in a dose-dependent manner. In conclusion, the extraction process of SNPS established in this study is reliable, and SNPS possesses potential antioxidant and anti-inflammatory activities, which will provide a theoretical basis for guiding the clinical application of $S$. ningpoensis.
\end{abstract}

\section{Introduction}

The roots of Scrophularia ningpoensis Hemsl. (Radix Scrophulariae ningpoensis) are a perennial plant which belongs to the Scrophulariaceae family. Its dried roots are known in China as Xuanshen, a traditional medicine that has been used as an antipyretic and for the treatment of sore throat and prurigo for over 1000 years $[1,2]$. It has also been used as a health food. The main chemical substances of the roots of S. ningpoensis include iridoids, alkaloids, flavonoids, essential oils, and carbohydrates, which have been reported to possess anti-inflammatory actions [3-5]. Moreover, these plant-derived bioactive components are characterized by potential antioxidant activities [6,7]. However, few studies focused on the activity of polysaccharides from S. ningpoensis (SNPS). Polysaccharides are among the most active substances found in nature, with a variety of biological activities, such as antitumour, antioxidation, anti-inflammation, and immune regulation, with relatively low toxicity and side effects [8-10].

The development of efficient extraction methods for polysaccharides is important. The main polysaccharides 
extraction methods include hot water extraction (HWE), ultrasonic-assisted extraction (UAE), enzyme-assisted extraction (EAE), and microwave-assisted extraction (MAE) [11-14]. The UAE method utilizes the mechanical and thermal action generated by the high-frequency oscillation of ultrasonic waves, which results in a sharp increase in the frequency and rate of movement of the molecules inside the materials, thereby causing the rupture of the tissues and cells and the release of the active ingredients. This method is widely used, simple to operate, and associated with high extraction efficiency $[15,16]$. More importantly, UAE has potential advantages of protecting the structure and biological activity of active components [17-19].

In this study, the water-soluble polysaccharides from S. ningpoensis were extracted using the UAE method, and the extraction process was optimized by single-factor experiments and response surface method (RSM). After the deproteinization of the crude polysaccharides obtained from S. ningpoensis, the structure and monosaccharide compositions of SNPS were determined using Fourier transform infrared spectroscopy (FTIR) and high-performance liquid chromatography (HPLC), respectively. To further investigated the antioxidant potential of SNPS, 2,2-diphenyl-1-picrylhydrazyl (DPPH) radical, hydroxyl free radical, and 2,2'-azinobis (3-ethylbenzothiazoline-6-sulfonic acid) (ABTS) radical scavenging tests were performed. Simultaneously, lipopolysaccharide (LPS) induced in vivo inflammatory mice model was used to detect the anti-inflammatory activities of SNPS. These results will provide a theoretical basis for the further development and utilization of polysaccharides from S. ningpoensis.

\section{Materials and Methods}

2.1. Chemicals and Reagents. The roots of S. ningpoensis were collected from the experimental field of Jining Medical University (Rizhao, Shandong, China) and identified by Jian'an Wang (Medical Botanist, Jining Medical University). Monosaccharide standards D-glucose (D-Glc), D-galactose (D-Gal), D-arabinose (D-Ara), L-fucose (LFuc), D-mannose (D-Man), L-rhamnose (L-Rha), D-fructose (D-Fru), D-xylose (D-Xyl), D-GlcA, and D-GalA were purchased from Sigma-Aldrich (St. Louis, MO, USA). 2,2-Diphenyl-1-picrylhydrazyl (DPPH) free radical was purchased from Sigma-Aldrich (St. Louis, MO, USA). 2,2'-azinobis (3-ethylbenzothiazoline-6-sulfonic acid) (ABTS) free radical was purchased from the Shanghai Yuanye Biotechnology Co. Ltd. (Shanghai, China). ImProm-II Reverse Transcription System was obtained from Promega Corporation (Madison, WI, USA). IL-6 Mouse ELISA Kit was purchased from Invitrogen (Carlsbad, CA, USA). TNF- $\alpha$ Mouse ELISA Kit was obtained from PeproTech (Rocky Hill, NJ, USA). UNIQ-10 column Trizol total RNA extraction kit was obtained from Sangon Biological Engineering Technology and Services Co., Ltd. (Shanghai, China). FastStart Universal SYBR Green Master (ROX) kit was purchased from Roche (Mannheim, Germany). All chemical reagents were of analytical grade, and the deionized water was used in the whole experiment.
2.2. Pretreatment of the Roots of S. Ningpoensis. After washing the roots of $S$. ningpoensis, they were drained and then dried under vacuum at $65^{\circ} \mathrm{C}$. Root powder was obtained after pulverizing and sifting the dried roots with a 40-mesh sieve. Subsequently, the dried powder was mixed with acetone (at a ratio of $1: 5$ ) to remove fat-soluble substances by uniformly stirring for $24 \mathrm{~h}$. The precipitate was concentrated and lyophilized $\left(40^{\circ} \mathrm{C}, 12 \mathrm{~h}\right)$ to obtain the pretreated root sample.

2.3. Ultrasonic-Assisted Extraction Process. UAE was performed according to the described procedure of Jian-Hua Xie with slight modifications [20]. In detail, a total of $5.0 \mathrm{~g}$ of the pretreated $S$. ningpoensis powder was extracted by adding $150 \mathrm{~mL}$ deionized water. The reaction system was placed in an ultrasonic cell pulverizer (Xinyi 1200E, Ningbo Xinyi Ultrasonic Equipment Co., Ltd., Ningbo, China) with a low constant temperature tank (DC-8006, Ningbo Xinyi Ultrasonic Equipment Co., Ltd., Ningbo, China). The ultrasonic power was set to $285,380,475,570$, and $665 \mathrm{~W}$, respectively. The extraction temperature was set to $30,40,50$, 60 , and $70^{\circ} \mathrm{C}$, respectively. The extraction time was set to 5 , $15,25,35$, and $45 \mathrm{~min}$, respectively. The solutions obtained after the reactions were diluted with a quadruple volume of absolute ethanol to a final alcohol content of $80 \%$, and the mixtures were stored at $4^{\circ} \mathrm{C}$ overnight and then centrifuged at $3500 \mathrm{rpm}$ for $15 \mathrm{~min}$. The precipitates were freeze-dried to obtain the crude polysaccharides. The resulting crude SNPS were redissolved in deionized water, deproteinized according to the method reported by Sevag et al. [20], and lyophilized to obtain purified SNPS for subsequent analysis.

The extract yield of SNPS was determined by the phenol sulfuric acid method with minor modification [21] and calculated according to the following formula:

$$
\text { Extraction yield }(\%)=\frac{C \times V}{W} \times 100 \%,
$$

where $C(\mathrm{mg} / \mathrm{mL})$ is the concentration of the SNPS solution, $V$ is the dilution factor, and $\mathrm{W}$ is the dry weight of the pretreated powder.

2.4. Optimization of Extraction Process. Based on the results of monofactor tests, RSM was further used to optimize the extraction parameters. BBD was applied to determine the effect of extract temperature $\left(X_{1},{ }^{\circ} \mathrm{C}\right)$, ultrasonic power $\left(X_{2}\right.$, $W$ ), and extract ultrasonic time $\left(X_{3}, \mathrm{~min}\right)$ at three levels on the extraction yield of SNPS. As shown in Table 1, the above 3 factors were designed at three levels respectively, and $-1,0$, and 1 represented the low, medium, and high levels of the independent variables, respectively.

Based on experiment results from $\mathrm{BBD}$, a second-order polynomial model was performed as follows:

$$
Y=A_{o}+\sum_{i=1}^{3} A_{i} X_{i}+\sum_{i=1}^{3} A_{i i} X_{i}^{2}+\sum_{i=1}^{2} \sum_{i=j+1}^{3} A_{i j} X_{i} X_{j}
$$

where $Y$ is the response variable (extraction yield of SNPS); $A_{0}$ is a constant, $A i$ is the linear coefficient, $A i i$ is the 
TABLE 1: Coded and uncoded levels of independent variables used for BBD.

\begin{tabular}{lccc}
\hline Independent variable & \multicolumn{3}{c}{ Coded levels } \\
& -1 & 0 & 1 \\
\hline Ultrasonic temperature $\left(X_{1}\right)\left({ }^{\circ} \mathrm{C}\right)$ & 30 & 50 & 70 \\
Ultrasonic power $\left(X_{2}\right)(\mathrm{W})$ & 285 & 475 & 665 \\
Ultrasonic time $\left(X_{3}\right)(\mathrm{min})$ & 15 & 25 & 35 \\
\hline
\end{tabular}

quadratic coefficient, and $A i j$ is the interaction coefficient. $X i$ and $X j$ are independent variables $(i \neq j)$.

2.5. Monosaccharide Component Analysis. The monosaccharide component was determined by HPLC (Waters1525, Waters Co., USA). A total of $2.0 \mathrm{mg}$ SNPS sample was mixed with $1 \mathrm{~mL}$ trifluoroacetic acid (TFA, $2 \mathrm{~mol} / \mathrm{L}$ ) and then hydrolyzed in an oven at $121^{\circ} \mathrm{C}$ for $2 \mathrm{~h}$. Subsequently, the volume was adjusted to $50 \mathrm{~mL}$ with water, and the mixture was filtered with a $0.45 \mu \mathrm{m}$ microporous membrane for HPLC analysis. All standard sugars were prepared according to the same method. The sample and standards were analyzed by ion chromatography using ICS-5000 ion chromatograph (Dean Inc., USA) with a pulsed amperometric detector (PAD) as previously reported [22], with some modifications. An UltrahydrogelTM Linear column $(300 \mathrm{~mm} \times 7.8 \mathrm{~mm})$ was used with a flow rate of $0.5 \mathrm{~mL} / \mathrm{min}$. The detailed liquid phase was shown in Table 2.

2.6. FT-IR Analysis of SNPS. A total of $1.0 \mathrm{mg}$ of SNPS was mixed with potassium bromide for tableting, and the dried polysaccharides were subjected to $4000-400 \mathrm{~cm}^{-1}$ scanning using FT-IR (IR Tracer-21, Shimadzu Corporation, Tokyo, Japan).

2.7. DPPH Radical Scavenging Activity of SNPS. The DPPH radical scavenging activity of SNPS was evaluated as previously reported [23], with slight modifications. Briefly, SNPS solutions were diluted with DPPH-ethanol solution and incubated at room temperature in the dark for $30 \mathrm{~min}$. The DPPH solution was replaced with anhydrous ethanol in the control tube, and the polysaccharides solution was replaced with distilled water in the blank tube. The absorbance of each solution was measured at a wavelength of $517 \mathrm{~nm}$ and ascorbic acid (Vitamin $c, \mathrm{Vc}$ ) was used as a positive control. The scavenging rate was calculated according to the following formula:

$$
\text { Scavenging activity }(\%)=\left(1-\frac{A_{S}-A_{C}}{A_{b}}\right) \times 100 \text {, }
$$

where $A_{s}$ was the absorbance of DPPH-ethanol solution, deionized water and SNPS samples, $A_{c}$ was the absorbance of SNPS solution with equivolumetric anhydrous ethanol instead of DPPH, $A_{b}$ was the absorbance of DPPH solution with equivolumetric deionized water (without SNPS).

2.8. Hydroxyl Free Radical Scavenging Rate of SNPS. The hydroxyl radicals scavenging activity of SNPS was
TABle 2: Mobile phase and gradient for monosaccharide composition analysis.

\begin{tabular}{lccc}
\hline Time (min) & Water $(\%)$ & $\mathrm{NaOH}(250 \mathrm{mM}, \%)$ & $\mathrm{NaAc}(1 \mathrm{M}, \%)$ \\
\hline 0 & 97.4 & 2.6 & 0 \\
21 & 97.4 & 2.6 & 0 \\
21.1 & 92.4 & 2.6 & 5 \\
30 & 77.4 & 2.6 & 20 \\
30.1 & 20 & 80 & 0 \\
50 & 20 & 80 & 0 \\
\hline
\end{tabular}

determined according to the method reported by Li with a slight modification [24]. In short, SNPS was added sequentially with $2.0 \mathrm{~mL}$ ferrous sulfate solution $(9 \mathrm{mmol} / \mathrm{L}$, $\left.\mathrm{FeSO}_{4}\right), 2.0 \mathrm{~mL}$ salicylic acid in ethanol $\left(9 \mathrm{mmol} / \mathrm{L}, \mathrm{C}_{7} \mathrm{H}_{6} \mathrm{O}_{3}\right)$, and $2.0 \mathrm{~mL}$ hydrogen peroxide solution $\left(9 \mathrm{mmol} / \mathrm{L}, \mathrm{H}_{2} \mathrm{O}_{2}\right)$. The mixtures were shaken well and incubated at $37^{\circ} \mathrm{C}$ for $30 \mathrm{~min}$. Deionized water was used as a reference and the absorbance was measured at a wavelength of $510 \mathrm{~nm}$. Vc of the same mass concentration was used as a positive control. The scavenging rate was calculated according to equation (3), where As was the absorbance of the samples in the $\mathrm{FeSO}_{4}-\mathrm{C}_{7} \mathrm{H}_{6} \mathrm{O}_{3}$ reaction system, Ac was the absorbance of the samples in deionized water, and $\mathrm{Ab}$ was the absorbance of the $\mathrm{FeSO}_{4}-\mathrm{C}_{7} \mathrm{H}_{6} \mathrm{O}_{3}$ reaction system with deionized water.

2.9. ABTS Free Radical Scavenging Rate of SNPS. The ABTS radical scavenging activity of SNPS was determined using a modified method, according to $\mathrm{Re}$ et al. [25]. Equivalent amounts of $7 \mathrm{mmol} / \mathrm{L}$ ABTS solution and $2.45 \mathrm{mmol} / \mathrm{L}$ potassium persulfate solution were mixed and incubated at room temperature in the dark for $12-16 \mathrm{~h}$ to prepare the $\mathrm{ABTS}^{+}$stock solution. Then the $\mathrm{ABTS}^{+}$assay solution was obtained by diluting the stock solution with distilled water. Different concentrations of SNPS samples were mixed with $\mathrm{ABTS}^{+}$assay solution followed by incubation at room temperature in the dark for $60 \mathrm{~min}$. The absorbance was measured immediately at $734 \mathrm{~nm}$. Vc was used as a positive control. The ABTS radical scavenging activity was calculated using equation (3), with ABTS solution instead of DPPH.

2.10. In Vivo Anti-Inflammatory Evaluation of SNPS. Male-specific pathogen-free (SPF) grade imprinting control region (ICR) mice (18-22 g) were purchased from Qingdao Daren Fortune Animal Technology Co., Ltd (Qingdao, China). All mice were housed under controlled environmental conditions (temperature, $22 \pm 1^{\circ} \mathrm{C}$; relative humidity, $50 \pm 5 \%$; light/dark cycle, $12 \mathrm{~h}$ ). The animal experiments were conducted according to the NIH Guide for the Care and Use of Laboratory Animals and the protocol was approved by the Ethics Committee of Jining Medical University.

After adaptation for 7 days, a total of 48 mice were randomly assigned into 6 groups $(n=8)$ : (1) Normal control group; (2) Model group; (3) Positive group (aspirin $10 \mathrm{mg} /$ kg); (4-6) SNPS (100, 200 or $400 \mathrm{mg} / \mathrm{kg}$, respectively). SNPS was dissolved in sterile pyrogen-free saline solution. The mice in the normal control group and model group were 
gastrointestinally treated with $0.9 \%$ saline for 4 days (once per day). Mice in the positive group and the SNPS group were treated with aspirin and corresponding dosages of SNPS, respectively, for 4 days, once per day. Thirty minutes after the final administration, the mice (in addition to the control group) were intraperitoneally injected with LPS $(1 \mathrm{mg} / \mathrm{kg})$. The mice in the control group were treated with equal volumes of saline. After $90 \mathrm{~min}$, all mice were sacrificed by diethyl ether asphyxiation. The blood was collected, and serum was prepared and stored at $-20^{\circ} \mathrm{C}$ for the detection of protein levels of TNF- $\alpha$ and IL-6. Simultaneously, the liver tissues were harvested and weighed; the liver tissues were used for the determination of the mRNA expression.

2.11. Real-Time RT-PCR Assay. The mRNA expressions of IL- 6 and TNF- $\alpha$ in the mouse liver were detected by realtime RT-PCR. In brief, the liver tissues (approximately $50 \mathrm{mg}$ ) were homogenized in $500 \mu \mathrm{L}$ Trizol, and the total RNA was isolated using a Sangon UNIQ-10 column Trizol total extraction kit. Then, reverse transcriptions were performed using the ImProm-II Reverse Transcription System cDNA synthesis kit according to the manufacturer's instructions. The real-time RT-PCR oligonucleotide primers used for the mouse IL-6, TNF- $\alpha$, and $\beta$-actin (an internal control) are listed in Table 3 . The reaction processes were performed as previously described [26].

2.12. Analysis for Serum IL-6 and TNF- $\alpha$ Expression. The serum concentrations of TNF- $\alpha$ and IL- 6 were detected according to the commercial ELISA kits. The serum samples for TNF- $\alpha$ and IL- 6 were assayed at a 100-fold and 50-fold dilution in the assay buffer, respectively.

2.13. Statistical Analyses. Statistical analysis was performed using the Origin 8.0 software (Northampton, MA, USA). In vitro, data were expressed as the means \pm S.D. from three independent experiments. In vivo, data were expressed as the means \pm S.E. Differences between groups were analyzed by one-way analysis of variance (ANOVA). A $P$-value less than 0.05 was considered statistically significant.

\section{Results and Discussion}

3.1. Effect of Ultrasonic Power on the Yield of SNPS. In this study, the UAE method was applied to extract SNPS from the roots of $S$. ningpoensis. The extraction power, temperature, and time were evaluated, and the results are shown in Figure 1. To examine the effect of the ultrasonic power on the extraction efficiency, the ratio of material to liquid, extraction temperature, and extraction time was set as $1: 30 \mathrm{~g} /$ $\mathrm{mL}, 50{ }^{\circ} \mathrm{C}$ and $25 \mathrm{~min}$, respectively. As shown in Figure 1(a), with an ultrasonic power of $475 \mathrm{~W}$, the extraction efficiency reached its maximum of $12.45 \% \pm 0.16 \%$. Subsequently, however, the extraction yield decreased with a further increase of ultrasonic power. The ultrasonic power, therefore, had a significant influence on the extraction yield. We speculated that higher ultrasonic power would induce the degradation of polysaccharides [27]. Therefore, $475 \mathrm{~W}$ was chosen as the optimal extraction power for subsequent optimization experiments.

\subsection{Effect of Ultrasonic Temperature on the Yield of SNPS.} A total of $5.0 \mathrm{~g}$ of acetone-extracted S. ningpoensis powder was weighed accurately. The ratio of material to liquid, ultrasonic power, and extraction time was set as $1: 30 \mathrm{~g} / \mathrm{mL}$, $475 \mathrm{~W}$, and $25 \mathrm{~min}$, respectively, in order to detect the effect of temperature on the extraction efficiency. When the temperature increased, the vapor pressure made more solvent vapors enter the bubble cavity and induce the collapse of the cell wall. Thus, it made the solvent penetrate deeply into the sample matrix, resulting in higher extraction efficiency. As shown in Figure 1(b), a maximum yield of $13.21 \% \pm 0.087 \%$ was observed at $50^{\circ} \mathrm{C}$. The extraction efficiency decreased at higher temperatures, likely due to the increased dissolution of impurities [28, 29].

3.3. Effect of Extraction Time on the Yield of SNPS. The effect of the ultrasonic time on the yield of SNPS was investigated from 5 to $45 \mathrm{~min}$, with other extraction conditions fixed as follows: the ratio of material to liquid, $1: 30 \mathrm{~g} / \mathrm{mL}$; ultrasonic power, $475 \mathrm{~W}$; and temperature, $50^{\circ} \mathrm{C}$. As shown in Figure 1(c), the yield of SNPS increased from $10.90 \% \pm 0.073 \%$ to $13.35 \% \pm 0.10 \%$ from 5 to $25 \mathrm{~min}$, respectively. The yield then decreased with increasing extraction time, likely due to the ultrasonic cavitation energy, which generated many cavities on the external surface of the plant's cell wall, thus accelerating the release of the bioactive constituents into the liquid [30]. A previous study showed that excessive ultrasonication durations cause polysaccharide degradation [31]. According to the results from the single-factor studies, extraction power, temperature, and time significantly affected the yield of SNPS. Therefore, we further optimized these three parameters.

\subsection{Optimization of SNPS Extraction by BBD}

3.4.1. Fitting the Model. The effect of the extraction temperature $\left(X_{1}\right)$, ultrasonic power $\left(X_{2}\right)$, and ultrasonic time $\left(X_{3}\right)$ on the extraction yield of SNPS was evaluated at three levels using BBD. The results are shown in Table 4. The yield of SNPS ranged from $10.56 \% \pm 0.69 \%$ to $13.71 \% \pm 1.63 \%$. Experiment 14 (extraction temperature, $50^{\circ} \mathrm{C}$; extraction power, $475 \mathrm{~W}$; extraction time, $25 \mathrm{~min}$ ) produced the highest yield, while experiment 5 (extraction temperature, $30^{\circ} \mathrm{C}$; extraction power, $475 \mathrm{~W}$; extraction time, $15 \mathrm{~min}$ ) produced the lowest yield. The following second-order polynomial was obtained by multiple regression analysis:

$$
\begin{aligned}
\text { Yield } \%= & 13.38+0.071 X_{1}+0.43 X_{2}+0.27 X_{3} \\
& +0.20 X_{1} X_{2}-0.38 \times 1 \times 3+0.077 X_{2} X_{3} \\
& -0.82\left(X_{1}\right)^{2}-0.57\left(X_{2}\right)^{2}-1.10\left(X_{3}\right)^{2} .
\end{aligned}
$$

According to the ANOVA of the quadratic regression model (Table 5), the values of determination coefficient $R^{2}$ was 0.954 , indicating that $95.4 \%$ of the variables can be 
TABLE 3: The real-time RT-PCR oligonucleotide primers.

\begin{tabular}{lccc}
\hline Gene & Primer & Sequence (5'-3') & PCR product (bp) \\
\hline$\beta$-actin & Forward & TGTTACCAACTGGGACGACA & 165 \\
$($ NM_007393.3) & Reverse & GGGGTGTTGAAGGTCTCAAA & - \\
IL-6 & Forward & TCCAGTTGCCTTCTTGGGAC & 140 \\
$($ NM_031168.1) & Reverse & GTGTAATTAAGCCTCCGACTTG & - \\
TNF- $\alpha$ & Forward & TAGCCAGGAGGGAGAACAGA & 127 \\
$($ NM_013693.2) & Reverse & TTTTCTGGAGGGAGATGTGG & - \\
\hline
\end{tabular}

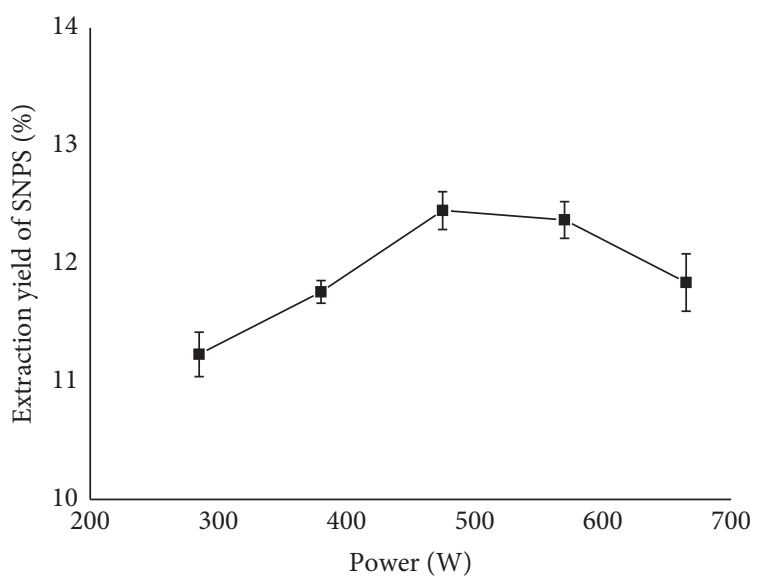

(a)

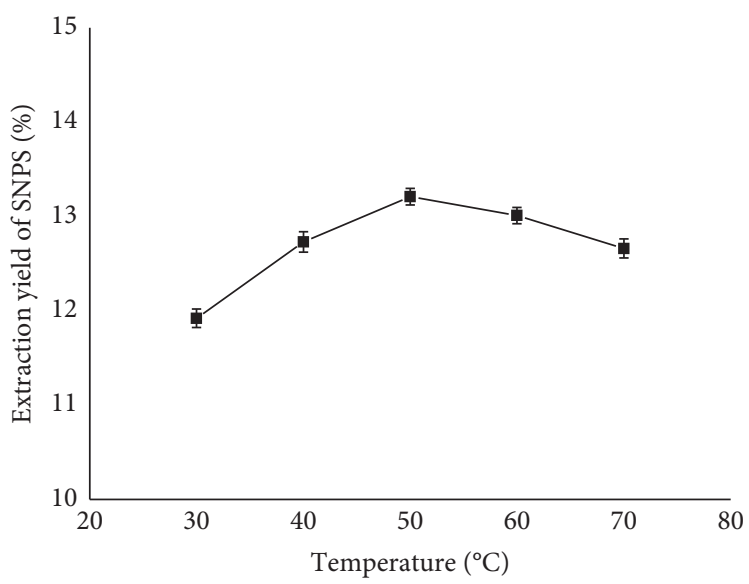

(b)

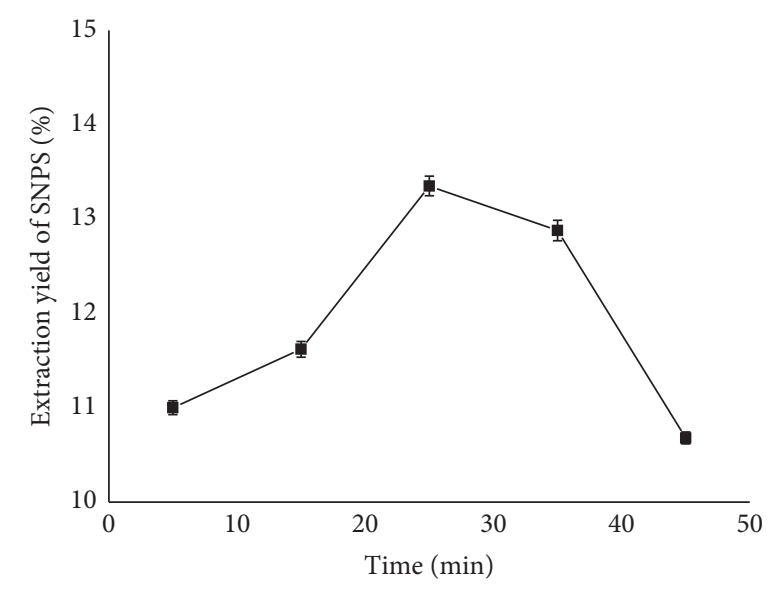

(c)

Figure 1: Effect of different extraction parameters on the yield of SNPS. (a) Ultrasonic power (W). (b) Extraction temperature $\left({ }^{\circ} \mathrm{C}\right)$. (c) Extraction time (min).

explained by the fitting model. The adjusted determination coefficient $R^{2}\left(R_{\text {adj }}^{2}, 0.895\right)$ indicated a relatively high degree of correlation between the experimental and predicted values. The coefficient of variation (C.V.\%) was 2.47 , indicating the reliability of the experimental values. The F-value (2.26) and $P$-value (0.224) of the lack-of-fit factor test represented there was no lack-of-fit factor in this model.

Furthermore, the linear coefficients $\left(X_{2}\right.$ and $\left.X_{3}\right)$, the quadratic term coefficients $\left(X_{1}^{2}, X_{2}^{2}\right.$, and $\left.X_{3}^{2}\right)$, and the interaction coefficient $\left(X_{1} X_{3}\right)$ affected the yield of SNPS highly significantly $(P<0.05$ or $P<0.01)$, while the other coefficients were not significant $(P>0.05)$. The F-value showed that the extraction yield was influenced by the three ultrasonic extraction parameters, in the following order: power $>$ time $>$ temperature; the interaction effects were in the following order: $X 1 X 3>X 1 X 2>X 2 X 3$. Therefore, the regression equation can be applied to demonstrate the real relationship between the extraction yield of SNPS and variables.

3.4.2. Diagnosis of Model Adequacy. Model adequacy is very vital for checking whether the established model would give a sufficient approximation to the actual values. Figure 2(a) shows the internally studentized residuals versus actual runs; all data points lay within the acceptable limits $( \pm 2)$. As 
TABLE 4: Box-Behnken design with independent variables and response values.

\begin{tabular}{|c|c|c|c|c|c|}
\hline \multirow{2}{*}{ Run } & \multicolumn{3}{|c|}{ Independent variables } & \multicolumn{2}{|c|}{ Response } \\
\hline & $X_{1}\left({ }^{\circ} \mathrm{C}\right)$ & $X_{2}(\mathrm{~W})$ & $X_{3}(\min )$ & Experimental yield (\%) & Predicted yield (\%) \\
\hline 1 & $-1(30)$ & $-1(285)$ & $0(25)$ & $11.55 \pm 0.99$ & 11.68 \\
\hline 2 & $1(70)$ & $-1(285)$ & $0(25)$ & $11.36 \pm 1.01$ & 11.43 \\
\hline 3 & $-1(30)$ & $1(665)$ & $0(25)$ & $12.23 \pm 1.11$ & 12.16 \\
\hline 4 & $1(70)$ & $1(665)$ & $0(25)$ & $12.82 \pm 0.87$ & 12.69 \\
\hline 5 & $-1(30)$ & $0(745)$ & $-1(15)$ & $10.56 \pm 0.69$ & 10.73 \\
\hline 6 & $1(70)$ & $0(745)$ & $-1(15)$ & $11.41 \pm 0.88$ & 11.64 \\
\hline 7 & $-1(30)$ & $0(745)$ & $1(35)$ & $12.27 \pm 1.00$ & 12.04 \\
\hline 8 & $1(70)$ & $0(745)$ & $1(35)$ & $11.59 \pm 0.93$ & 11.42 \\
\hline 9 & $0(50)$ & $-1(285)$ & $-1(15)$ & $11.37 \pm 1.12$ & 11.07 \\
\hline 10 & $0(50)$ & $1(665)$ & $-1(15)$ & $11.88 \pm 0.77$ & 11.78 \\
\hline 11 & $0(50)$ & $-1(285)$ & $1(35)$ & $11.37 \pm 0.83$ & 11.47 \\
\hline 12 & $0(50)$ & $1(665)$ & $1(35)$ & $12.19 \pm 1.03$ & 12.49 \\
\hline 13 & $0(50)$ & $0(745)$ & $0(25)$ & $13.22 \pm 1.10$ & 13.38 \\
\hline 14 & $0(50)$ & $0(745)$ & $0(25)$ & $13.71 \pm 1.63$ & 13.38 \\
\hline 15 & $0(50)$ & $0(745)$ & $0(25)$ & $13.39 \pm 0.92$ & 13.38 \\
\hline 16 & $0(50)$ & $0(745)$ & $0(25)$ & $13.49 \pm 0.88$ & 13.38 \\
\hline 17 & $0(50)$ & $0(745)$ & $0(25)$ & $13.08 \pm 1.12$ & 13.378 \\
\hline
\end{tabular}

Data show mean $\pm \operatorname{SD}(n=3)$.

TABLE 5: Analysis of variance (ANOVA) of the quadratic model and lack-of-fit.

\begin{tabular}{|c|c|c|c|c|c|c|}
\hline Source & Sum of squares & Df & Mean square & $F$-value & $P$ Value & Significance \\
\hline Model & 13.22 & 9 & 1.47 & 16.13 & 0.00007 & $* * *<0.0001$ \\
\hline$X_{1}$ & 0.041 & 1 & 0.041 & 0.45 & 0.5256 & - \\
\hline$X_{2}$ & 1.51 & 1 & 1.51 & 16.53 & 0.0048 & $* *<0.01$ \\
\hline$X_{3}$ & 0.60 & 1 & 0.60 & 6.64 & 0.0366 & $*<0.05$ \\
\hline$X_{1} X_{2}$ & 0.15 & 1 & 0.15 & 1.67 & 0.2372 & - \\
\hline$X_{1} X_{3}$ & 0.59 & 1 & 0.59 & 6.43 & 0.0389 & $*<0.05$ \\
\hline$X_{2} X_{3}$ & 0.024 & 1 & 0.024 & 0.26 & 0.6233 & - \\
\hline$X_{1}^{2}$ & 2.81 & 1 & 2.81 & 30.83 & 0.0009 & ${ }^{* * *}<0.0001$ \\
\hline$X_{2}^{2}$ & 1.38 & 1 & 1.38 & 15.10 & 0.0060 & ${ }^{* *}<0.01$ \\
\hline$X_{3}^{2}$ & 5.13 & 1 & 5.13 & 56.36 & 0.0001 & $* * *<0.0001$ \\
\hline Residual & 0.64 & 7 & 0.091 & - & - & - \\
\hline Lack-of-fit & 0.40 & 3 & 0.13 & 2.26 & 0.224 & - \\
\hline Pure error & 0.24 & 4 & 0.059 & - & - & - \\
\hline Cor total & 13.86 & 16 & - & - & - & - \\
\hline$R^{2}$ & 0.954 & - & - & - & - & - \\
\hline Adj. $R^{2}$ & 0.895 & - & - & - & - & - \\
\hline Adeq. Precision & 11.447 & - & - & - & - & - \\
\hline
\end{tabular}

C.V. $\%=2.47,{ }^{*}$ significant at 0.05 level; ${ }^{* *}$ significant at 0.01 level; ${ }^{* * *}$ significant at 0.001 level.

shown in Figure 2(b), the data points lay almost close to the straight line, indicating that the normality assumption was satisfied. Meanwhile, the plot of internally studentized residuals versus predicted response values (Figure 2(c)) showed that the residuals randomly scattered within the range of -3 and +3 in the $y$-axis, suggesting that the predicted response was within the acceptable limits. Therefore, these data implied that the present model was reliable.

3.4.3. Response Surface Analysis. A response surface analysis was performed, including the extraction yield, extraction conditions, and level of each extraction condition; this map highlights the influence of each extraction condition on the response value [32]. The values of the extraction conditions, and the interactions between the extraction conditions under optimal conditions, can be revealed by a contour map
[33]. In the present study, the $3 \mathrm{D}$ response surface and $2 \mathrm{D}$ contour plots showed the relationship between the extraction temperature $\left(X_{1}\right)$, extraction power $\left(X_{2}\right)$, extraction time $\left(X_{3}\right)$, and extraction yield of SNPS (Figure 3). Figures 3(a) and 3(b) illustrate the effect of extraction temperature and extraction power on the yield when the extraction time was set as $25 \mathrm{~min}$. The extract yield of SNPS initially increased when the extraction temperature and power increased in the range of $30-51.24^{\circ} \mathrm{C}$ and 285-550.63 W, respectively. However, with the above extract temperature of $51.24^{\circ} \mathrm{C}$ and ultrasonic power $550.63 \mathrm{~W}$, a decreased extract yield was observed. Thus, the highest yield was obtained with ultrasonic power of $550.63 \mathrm{~W}$ and extract temperature of $51.24^{\circ} \mathrm{C}$. In addition, the curved surface of the extraction power was steeper than that of the extraction temperature, suggesting that extraction power influenced 


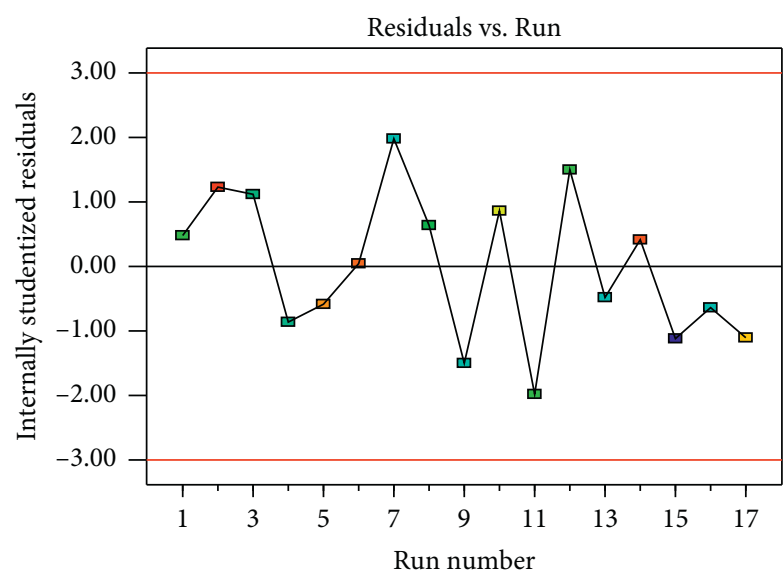

13.71
10.56

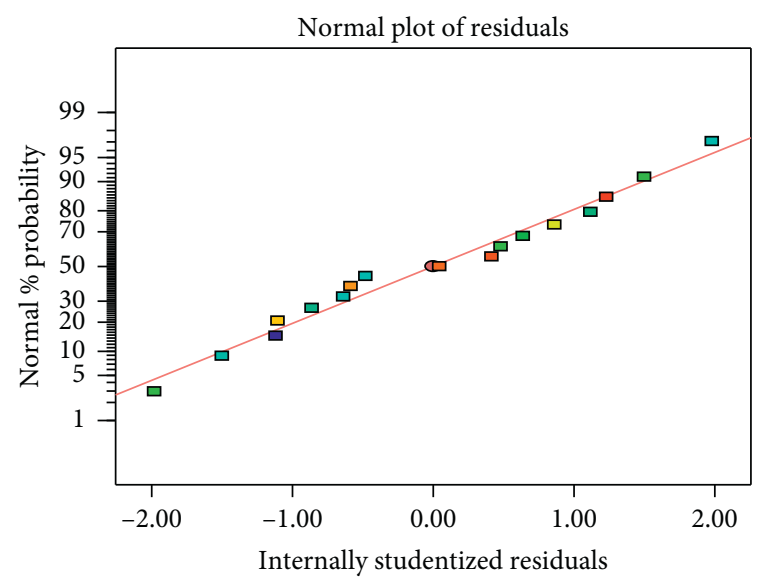

(b)

(a)

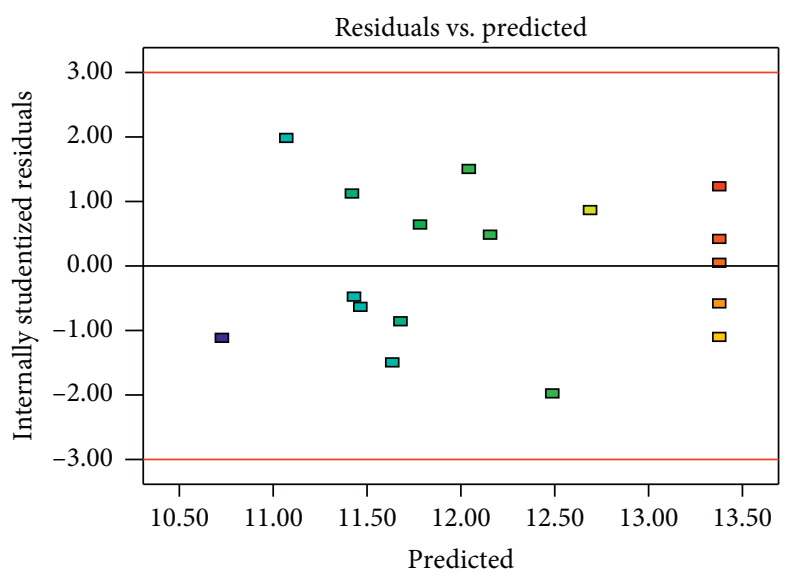

13.71

10.56

(c)

Figure 2: Diagnostic plots for the model adequacy. (a) The plot of internally studentized residuals vs. the actual run. (b) Normal probability plot of the studentized residuals. (c) Residuals vs. predicted plot graph.

the yield more significantly than that of the extraction temperature.

Figures 3(c) and 3(d) exhibit the effects of the extraction temperature and extraction time on the yield of SNPS. When fixing the extraction power at 475 (W), an obvious increase in the yield was observed with the extraction temperature increasing from $30^{\circ} \mathrm{C}$ to $51.24^{\circ} \mathrm{C}$, and the extraction time increasing from $5 \mathrm{~min}$ to $26.28 \mathrm{~min}$. However, the extraction yield decreased, followed by prolonging the ultrasonic time and temperature in the range of $26.28-45 \mathrm{~min}$ and $51.24-70^{\circ} \mathrm{C}$, respectively. The extraction yield of SNPS was the highest when the ultrasonic time was $26.28 \mathrm{~min}$, and the temperature was $51.24^{\circ} \mathrm{C}$. Statistically, the interaction effect between extraction temperature and time was significant $(P=0.0389$, as shown in Table 5$)$.

Figures 3(e) and 3(f) illustrate the interactions between the extraction power and extraction time on the yield of SNPS when fixing the temperature at $50^{\circ} \mathrm{C}$. When the ultrasonic power and time varied within the range of 285-550.63 (W) and 5-26.28 min, respectively, the extract yield gradually increased. However, the yield then decreased with increasing extraction time from $26.28 \mathrm{~min}$ to $45 \mathrm{~min}$ or ultrasonic power from $550.63 \mathrm{~W}$ to $665(\mathrm{~W})$. It indicated that SNPS was more likely to be degraded at a high extraction power. The yield of SNPS reached the maximum with ultrasonic power of $550.63 \mathrm{~W}$ and ultrasonic time of $26.28 \mathrm{~min}$.

3.4.4. Experimental Verification of the Regression Model. The optimal extraction conditions calculated from the model are as follows: ultrasonic time of $26.28 \mathrm{~min}$, the ultrasonic temperature at $51.24^{\circ} \mathrm{C}$, and ultrasonic power of $550.63 \mathrm{~W}$. Under this condition, the yield of SNPS reached to $13.48 \%$. To easy control the extraction parameters during actual operation, the optimal extraction conditions were corrected 


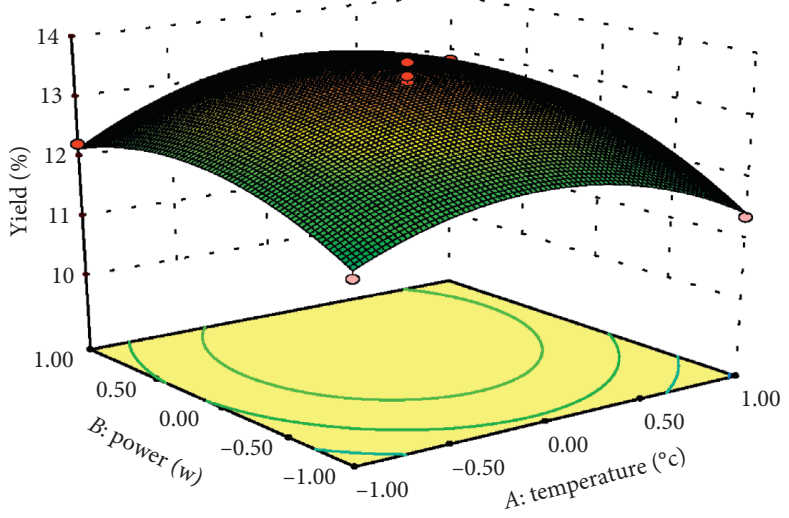

- Design points above predicted value - Design points below predicted value

$\prod_{10.56}^{13.71}$

10.56

(a)

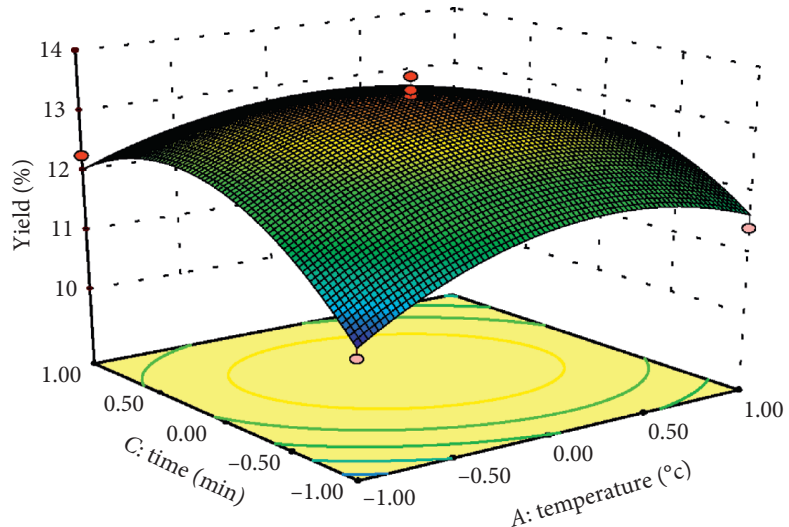

- Design points above predicted value - Design points below predicted value

13.71

10.56

(c)

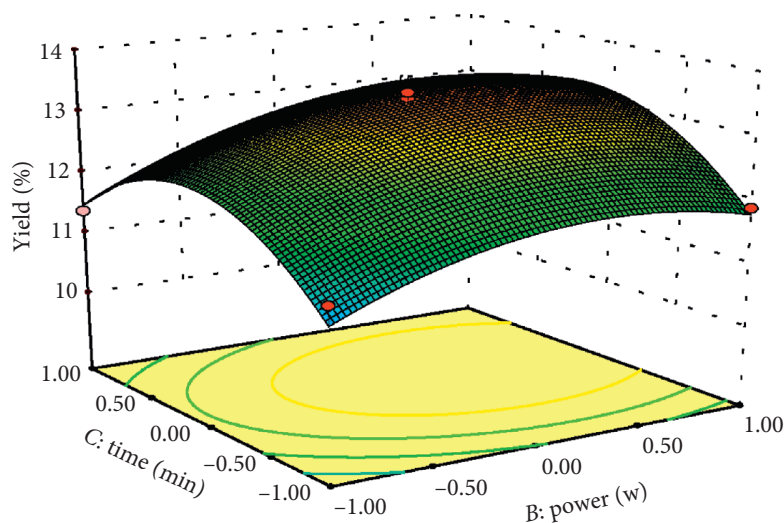

- Design points above predicted value

- Design points below predicted value

13.71
10.56

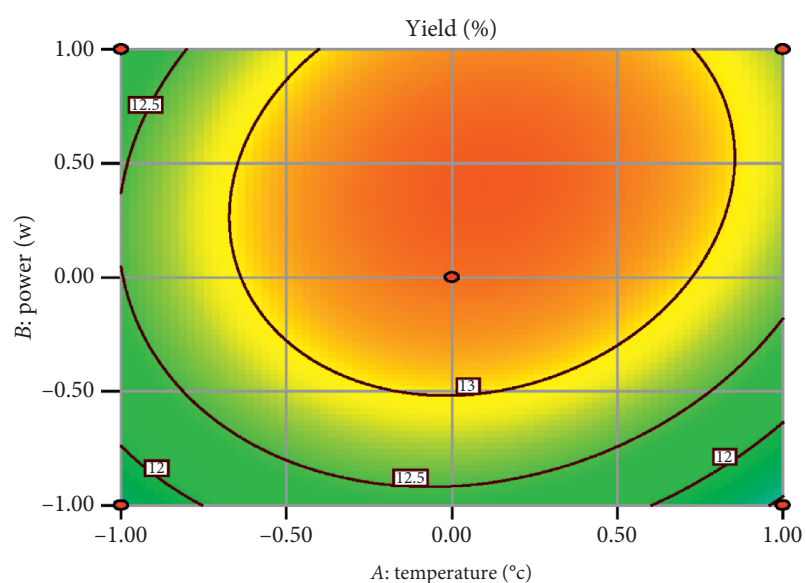

- Design points

$\bigoplus_{10.56}^{13.71}$

(b)

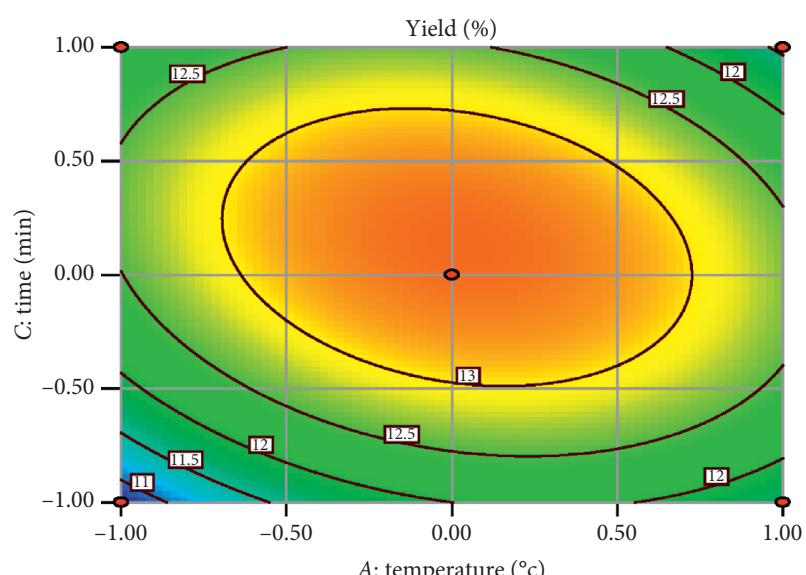

- Design points

13.71
10.56

(d)

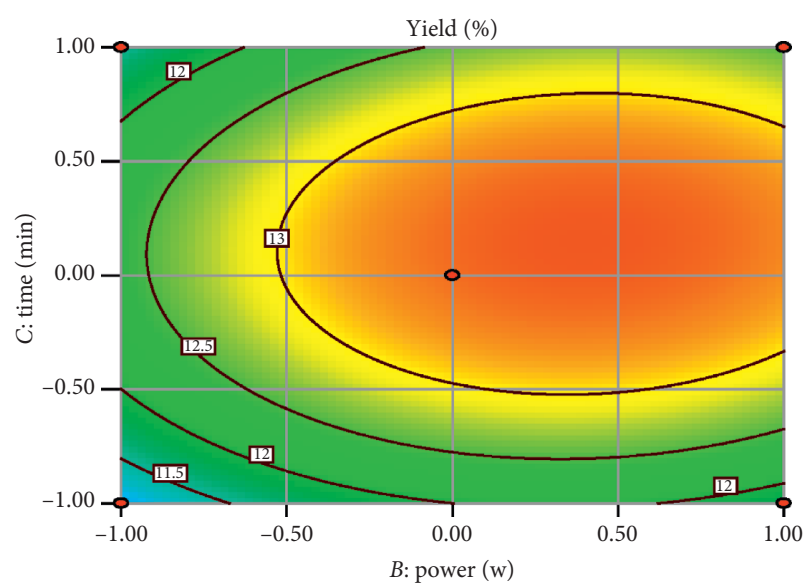

- Design points

13.71
10.56

(e)

Figure 3: Interactive effects of ultrasonic power, ultrasonic temperature, and ultrasonic time on the yield of SNPS. (a and b) Response surface and contour plots of the effect of ultrasonic power and temperature on the extraction rate of SNPS; (c and d) Response surface and contour plots of the effect of ultrasonic time and temperature on the extraction rate of SNPS; (e and f) Response surface and contour plots of the effect of ultrasonic power and time on the extraction rate of SNPS. 

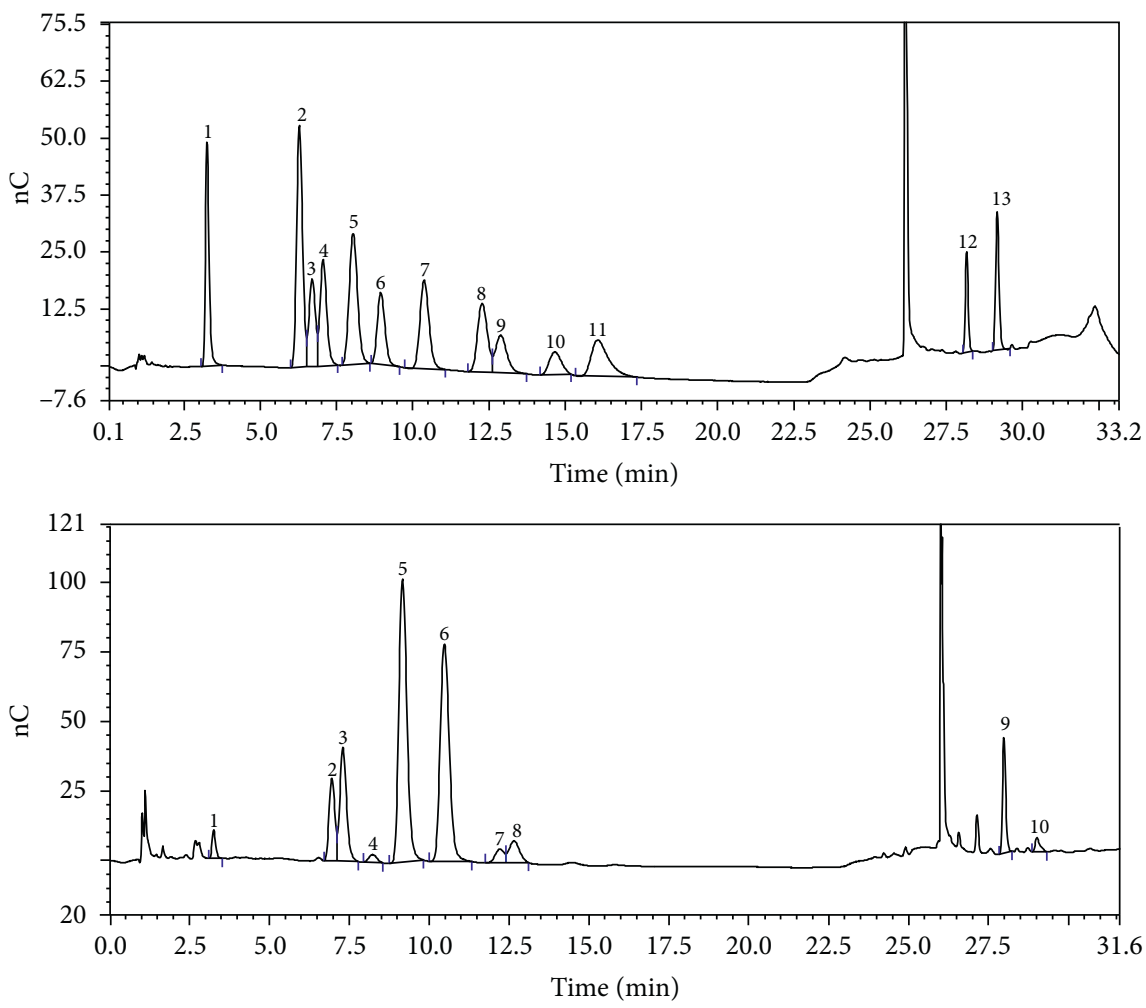

(a)

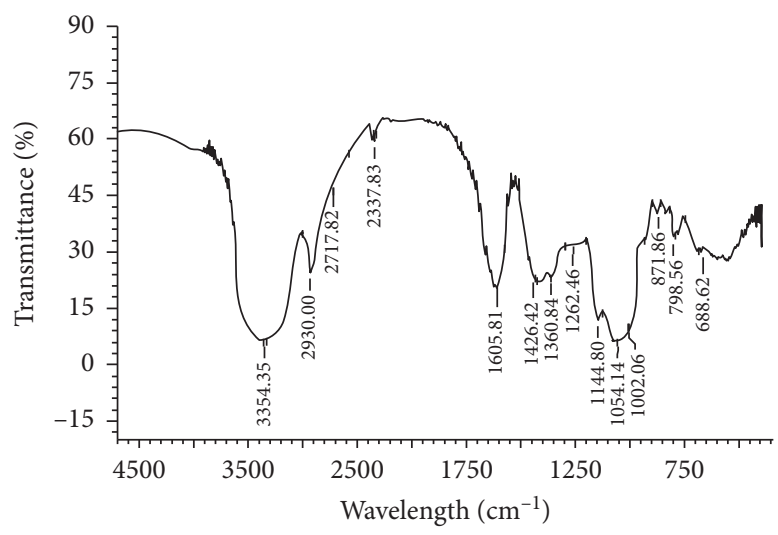

(b)

FIGURE 4: Characterization of SNPS. (a) HPLC analysis of monosaccharide components of SNPS (1. Fucose; 2. Rhamnose; 3 . Arabinose; 4. Galactosamine; 5. Galactose; 6. Glucose; 7. Xylose; 8. Mannose; 9. Galacturonic acid; 10. Glucuronic acid). (b) FT-IR analysis of SNPS.

with a slight modification of ultrasonic time of $26 \mathrm{~min}$, ultrasonic power of $550 \mathrm{~W}$, and temperature at $50^{\circ} \mathrm{C}$. Under these conditions, the actual extraction yield of SNPS was $13.47 \% \pm 1.63 \%(n=3)$, and the yield rate of purified polysaccharides extract $2.15 \% \pm 0.12 \%(n=3)$, suggesting that the parameters of the ultrasonic extraction condition optimized by the RSM are accurate and reliable.

3.5. Monosaccharide Composition and FT-IR Characterization of SNPS. The total carbohydrate content of SNPS was $91.53 \%$ as determined by the phenol sulfuric acid method. Total protein content of $1.086 \%$ was determined by the
Coomassie Brilliant Blue method. The monosaccharide composition determined by HPLC is shown in Figure 4(a). SNPS consisted of $1.30 \%$ fucose, $6.34 \%$ rhamnose, $9.95 \%$ arabinose, $0.82 \%$ aminogalactose, $29.98 \%$ galactose, $25.99 \%$ glucose, $1.56 \%$ xylose, $2.97 \%$ mannose, $4.86 \%$ galacturonic acid, and $0.90 \%$ glucuronic acid.

As shown in Figure 4(b), SNPS presents the typical absorption peaks of polysaccharides in the range of 4500$500 \mathrm{~cm}^{-1}$. The strong and broad signal at $3354 \mathrm{~cm}^{-1}$ corresponds to the $\mathrm{O}-\mathrm{H}$ stretching vibration in the constituent sugar residues [34]. The absorption peak at $2930 \mathrm{~cm}^{-1}$ represents a stretching vibration of the $\mathrm{C}-\mathrm{H}$ of the sugar ring. The absorption peaks at $1426 \mathrm{~cm}^{-1}$ and $1360 \mathrm{~cm}^{-1}$ were 


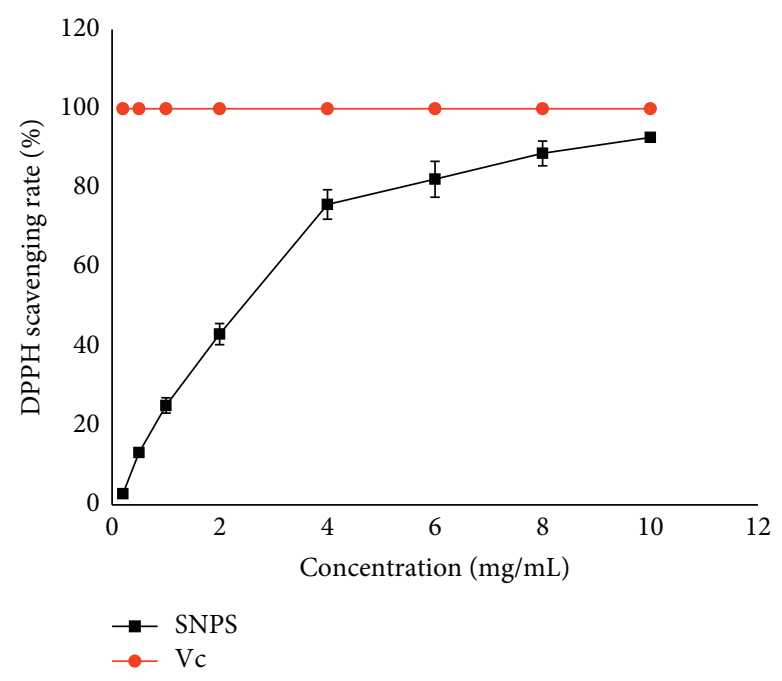

(a)

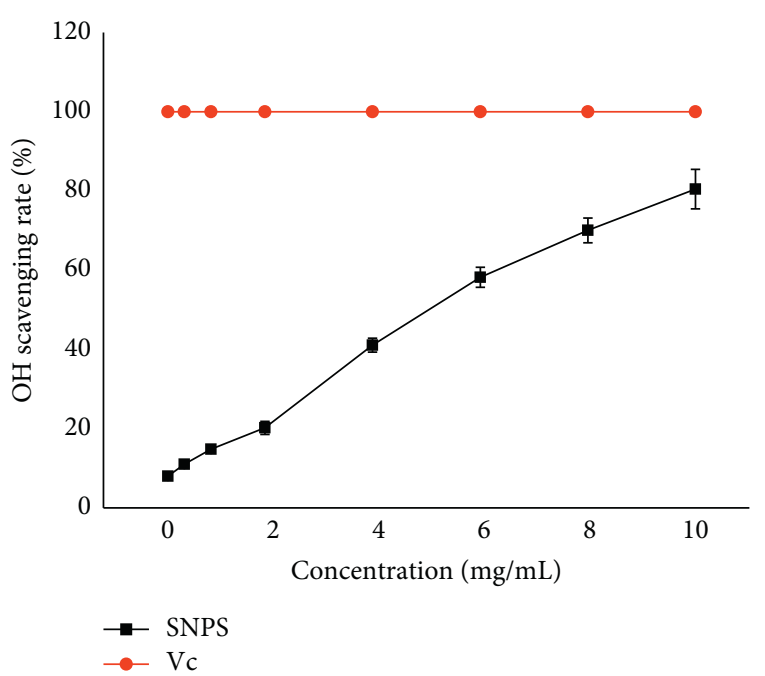

(b)

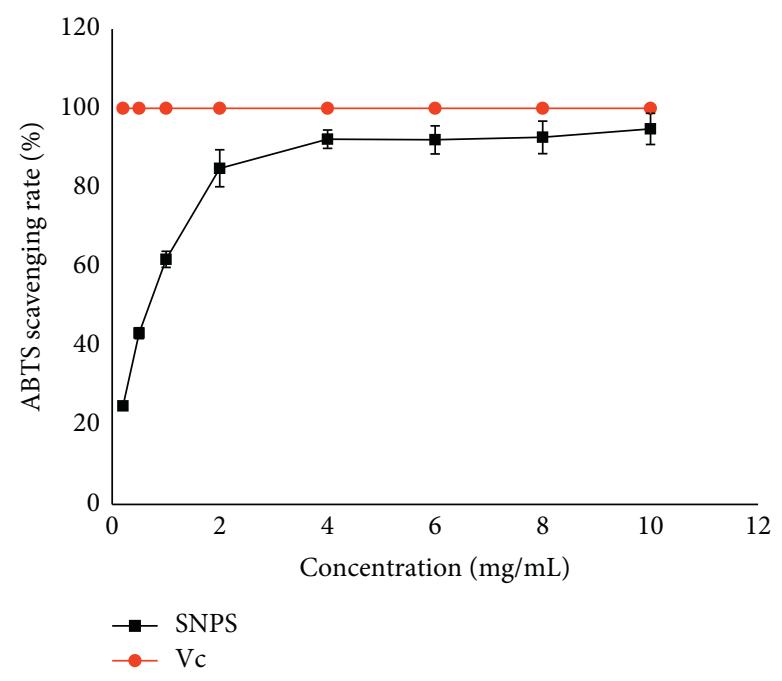

(c)

FIGURE 5: Antioxidant activities of SNPS. (a) Scavenging of DPPH radical. (b) Scavenging of OH free radical. (c) Scavenging of ABTS radical. Data are presented as the mean means \pm S.D., $n=4$. Vc was used as a positive control.

assigned to $\mathrm{C}-\mathrm{O}$ stretching vibrations. The strong absorptions at $1140 \mathrm{~cm}^{-1}, 1064 \mathrm{~cm}^{-1}$, and $1002 \mathrm{~cm}^{-1}$ indicate the vibrations of $\mathrm{C}-\mathrm{O}-\mathrm{C}$ and $\mathrm{C}-\mathrm{O}-\mathrm{H}$ bond [35].

3.6. Antioxidant Activities of SNPS. DPPH is a stable free radical that can accept an electron or hydrogen radical, forming a stable diamagnetic molecule with decreased absorbance at $517 \mathrm{~nm}$. DPPH has been widely used to investigate the radical scavenging activity of natural polysaccharides [36]. As shown in Figures 5(a) and 5(b), SNPS and the positive control $(\mathrm{Vc})$ exhibited obvious and concentration-dependent radical scavenging activity using $\mathrm{DPPH}$ radical and hydroxyl radical assay. The $\mathrm{EC}_{50}$ value of SNPS on DPPH and $\mathrm{OH}$ was $2.43 \pm 0.21 \mathrm{mg} / \mathrm{mL}$ and $4.40 \pm 0.35 \mathrm{mg} / \mathrm{mL}$, respectively.

The ABTS assay is a decolorization assay applicable for both lipophilic and hydrophilic antioxidants at different ${ }_{\mathrm{P}} \mathrm{H}$ levels [37]. The ABTS radical scavenging activities of SNPS and Vc are shown in Figure 5(c). Significant and dose-dependent ABTS scavenging activity was observed, even at SNPS concentrations $<1.0 \mathrm{mg} / \mathrm{mL}$. The maximum scavenging rate reached as high as $94.79 \%$ and the $\mathrm{EC}_{50}$ value was $0.56 \pm 0.062 \mathrm{mg} / \mathrm{mL}$. These data indicated that SNPS has a strong antioxidant activity.

3.7. Anti-Inflammatory Activities of SNPS. LPS is a prototypical bacterial endotoxin that can initiate a variety of inflammatory responses, resulting in the production of various proinflammatory cytokines, which causes liver damage in vitro [38]. In the early inflammatory response, IL- 6 and TNF- $\alpha$ play a vital role in evoking inflammation. In the present study, we measured the mRNA expression of IL- 6 and TNF- $\alpha$ to investigate the antiinflammatory action of SNPS to further confirm the 


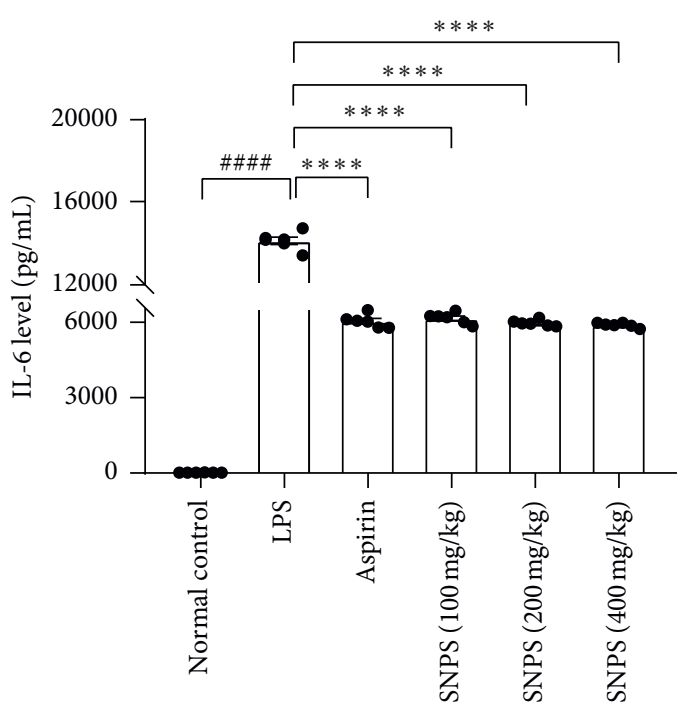

(a)

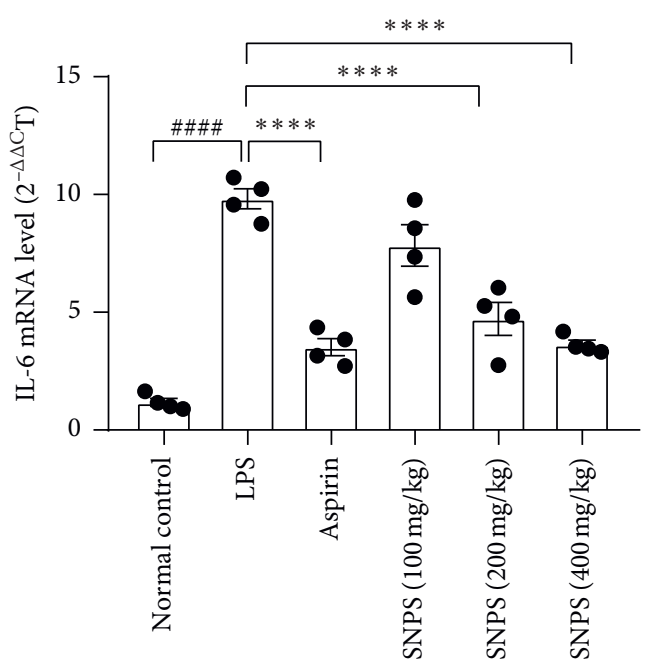

(c)

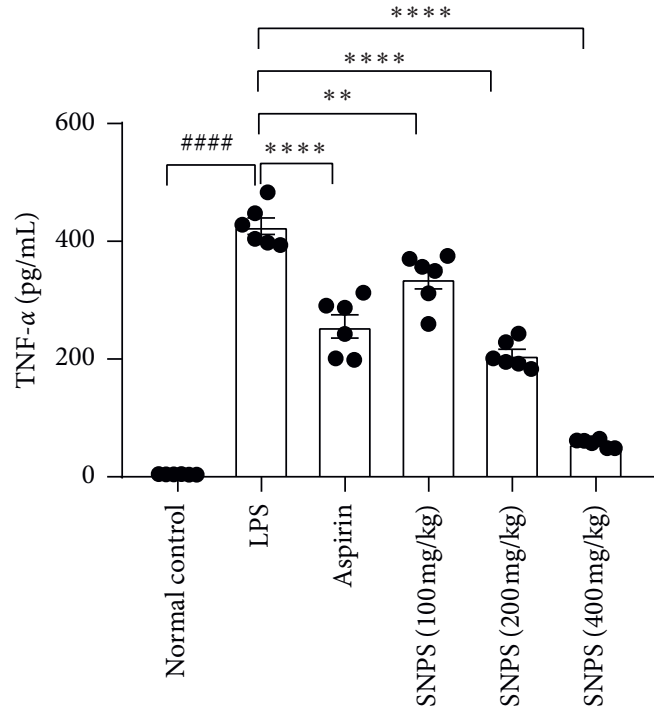

(b)

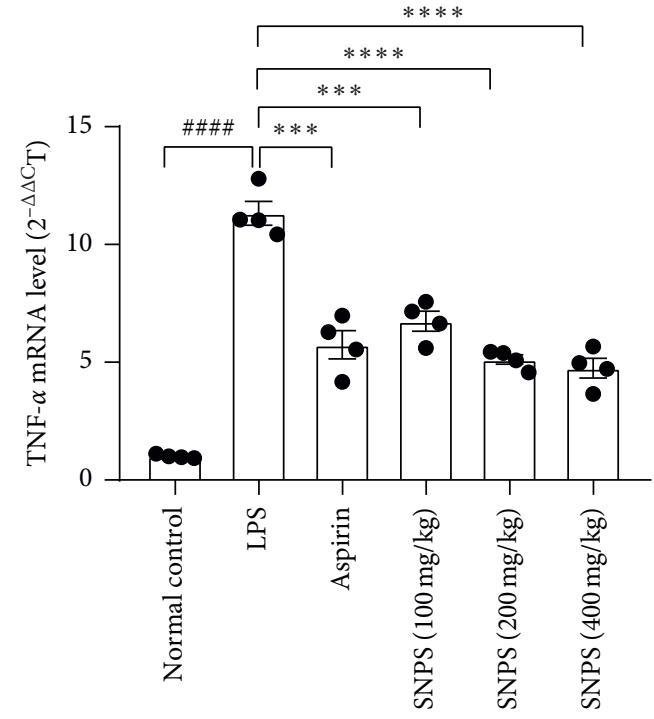

(d)

FIgURE 6: Anti-inflammatory activities of SNPS on LPS-induced mice. Mice were treated with SNPS (100, 200, and 400 mg/kg), aspirin $(10 \mathrm{mg} / \mathrm{kg}$ ), or saline for 4 days (once per day) and stimulated with LPS (1 mg/kg) for $90 \mathrm{~min}$. The protein expression of (a) IL-6 and (b) in serum were determined by ELISA. Values are means \pm S.E. $(n=6)$. The mRNA expression of IL- $6(\mathrm{c})$ and TNF- $\alpha(\mathrm{d})$ in the liver was measured using real-time RT-PCR. Values are means \pm S.E. $((n)=4)$. The $\beta$-actin was used as an internal control for real-time RT-PCR. Aspirin was used as a positive control. The significant difference compared with the normal control group, ${ }^{\# \# \# ~} P<0.0001$. The significant difference compared with LPS-treated alone, ${ }^{* *} P<0.01,{ }^{* * *} P<0.001,{ }^{* * *} P<0.0001$.

effectiveness of SNPS extraction. As displayed in Figures 6(a) and 6(b), LPS injection induced a burst of IL-6 and TNF- $\alpha$ secretion in the serum $(P<0.01)$ in comparison with the normal control group. However, the treatment of SNPS or aspirin significantly suppressed the overproduction of IL-6 and TNF- $\alpha(P<0.01)$. Additionally, the anti-inflammatory effect was more pronounced in the expression of TNF- $\alpha$, indicating that SNPS may be effective for early inflammation treatment. The effect of SNPS on the expression of IL- 6 and TNF- $\alpha$ mRNA in the liver was also investigated. As displayed in Figure 6(c) and 6(d), aspirin or SNPS treatment could effectively alleviate LPS-induced IL- 6 and TNF- $\alpha$ mRNA increment $(P<0.01)$. 


\section{Conclusion}

In the present study, an optimized UAE method was designed to extract polysaccharides from the roots of S. ningpoensis. Single-factor studies and RSM were employed to optimize the extraction conditions. At an optimal condition that ultrasonic power of $550 \mathrm{~W}$, extraction temperature of $50^{\circ} \mathrm{C}$, and extraction time of $26 \mathrm{~min}$, the highest yield of SNPS $(13.47 \% \pm 1.63 \%)$ was obtained. Compared with the traditional hot water extraction method (the yield was $11.5 \%$ ), the UAE method we applied significantly decreased extraction temperature and time and increased the extraction yield. The monosaccharide composition of SNPS analyzed by HPLC showed that SNPS was mainly composed of galactose and glucose, with lower levels of other monosaccharides. The FT-IR results illustrated that SNPS consisted primarily of carbohydrate substances, with no observed impurities. Furthermore, antioxidant and antiinflammatory evaluations revealed that SNPS exhibited good antioxidant and anti-inflammatory activities in a dose-dependent manner. In conclusion, we proposed a reliable extraction process of polysaccharides and the resulting SNPS possesses potential biological activities, which will provide a theoretical basis for guiding the clinical application of S. ningpoensis.

\section{Data Availability}

The datasets used in and/or analyzed during the current study available from the corresponding author on reasonable request.

\section{Conflicts of Interest}

The authors declare that they have no competing interests.

\section{Authors' Contributions}

Jian'an Wang and Lufen Huang contributed equally.

\section{Acknowledgments}

This work was supported by the National Natural Science Foundation of China (81903824), Special Subsidy for Public Health Service of Traditional Chinese Medicine in 2019 "National Survey of Traditional Chinese Medicine Resources" ([2019] no.39), and Supporting Fund for Teachers' research of Jining Medical University (Grant Nos. JY2017KJ047 and JYFC2019KJ015).

\section{References}

[1] P.-Y. Gong, Y.-W. He, J. Qi, C.-Z. Chai, and B.-Y. Yu, "Synergistic nourishing 'Yin' effect of iridoid and phenylpropanoid glycosides from Radix Scrophulariae in vivo and in vitro," Journal of Ethnopharmacology, vol. 246, Article ID 112209, 2020.

[2] S. Y. Sheu, Y. W. Hong, J. S. Sun, M. H. Liu, C. Y. Chen, and C. J. Ke, "Radix Scrophulariae extracts (harpagoside) suppresses hypoxia-induced microglial activation and neurotoxicity," BMC Complementary and Alternative Medicine, vol. 15, p. 324, 2015.

[3] Y.-F. Huo, H.-L. Wang, E.-H. Wei et al., "Two new compounds from the roots of Scrophularia ningpoensis and their anti-inflammatory activities," Journal of Asian Natural Products Research, vol. 21, no. 11, pp. 1083-1089, 2019.

[4] G. Zengin, A. Stefanucci, M. J. Rodrigues et al., "Scrophularia lucida L. as a valuable source of bioactive compounds for pharmaceutical applications: in vitro antioxidant, anti-inflammatory, enzyme inhibitory properties, in silico studies, and HPLC profiles," Journal of Pharmaceutical and Biomedical Analysis, vol. 162, pp. 225-233, 2019.

[5] A. Pasdaran and A. Hamedi, "The genus Scrophularia: a source of iridoids and terpenoids with a diverse biological activity," Pharmaceutical Biology, vol. 55, no. 1, pp. 2211-2233, 2017.

[6] C. Placines, V. Castañeda-Loaiza, M. João Rodrigues et al., "Phenolic profile, toxicity, enzyme inhibition, in silico studies, and antioxidant properties of Cakile maritima scop. (Brassicaceae) from southern Portugal," Plants, vol. 9, no. 2, p. 142, 2020.

[7] A. Della Valle, M. P. Dimmito, G. Zengin et al., "Exploring the nutraceutical potential of dried pepper capsicum annuum L. On market from altino in abruzzo region," Antioxidants, vol. 9, no. 5, p. 400, 2020.

[8] J.-K. Yan, L.-X. Wu, Z.-R. Qiao, W.-D. Cai, and H. Ma, "Effect of different drying methods on the product quality and bioactive polysaccharides of bitter gourd (Momordica charantia L.) slices," Food Chemistry, vol. 271, pp. 588-596, 2019.

[9] J. Liu, S. Willför, and C. Xu, "A review of bioactive plant polysaccharides: biological activities, functionalization, and biomedical applications," Bioactive Carbohydrates and Dietary Fibre, vol. 5, no. 1, pp. 31-61, 2015.

[10] J.-H. Xie, W. Tang, M.-L. Jin, J.-E. Li, and M.-Y. Xie, "Recent advances in bioactive polysaccharides from Lycium barbarum L., Zizyphus jujuba Mill, Plantago spp., and Morus spp.: structures and functionalities," Food Hydrocolloids, vol. 60, pp. 148-160, 2016.

[11] Y. Zhao, Y. Shi, H. Yang, and L. Mao, "Extraction of Angelica sinensis polysaccharides using ultrasound-assisted way and its bioactivity," International Journal of Biological Macromolecules, vol. 88, pp. 44-50, 2016.

[12] K. Feng, W. Chen, L. Sun et al., "Optimization extraction, preliminary characterization and antioxidant activity in vitro of polysaccharides from Stachys sieboldii Miq. tubers," Carbohydrate Polymers, vol. 125, pp. 45-52, 2015.

[13] D. U. Bhotmange, J. H. Wallenius, R. S. Singhal, and S. S. Shamekh, "Enzymatic extraction and characterization of polysaccharide from Tuber aestivum," Bioactive Carbohydrates and Dietary Fibre, vol. 10, pp. 1-9, 2017.

[14] Y. Yuan and D. Macquarrie, "Microwave assisted extraction of sulfated polysaccharides (fucoidan) from Ascophyllum nodosum and its antioxidant activity," Carbohydrate Polymers, vol. 129, pp. 101-107, 2015.

[15] D. C. Murador, A. R. C. Braga, P. L. G. Martins, A. Z. Mercadante, and V. V. de Rosso, "Ionic liquid associated with ultrasonic-assisted extraction: a new approach to obtain carotenoids from orange peel," Food Research International, vol. 126, Article ID 108653, 2019.

[16] F. Chemat, N. Rombaut, A.-G. Sicaire, A. Meullemiestre, A.-S. Fabiano-Tixier, and M. Abert-Vian, "Ultrasound assisted extraction of food and natural products. Mechanisms, techniques, combinations, protocols and applications. A review," Ultrasonics Sonochemistry, vol. 34, pp. 540-560, 2017. 
[17] T. Lin, Y. Liu, C. Lai, T. Yang, J. Xie, and Y. Zhang, "The effect of ultrasound assisted extraction on structural composition, antioxidant activity and immunoregulation of polysaccharides from Ziziphus jujuba Mill var. spinosa seeds," Industrial Crops and Products, vol. 125, pp. 150-159, 2018.

[18] X. Wang, Y. Wu, J. Li et al., "Ultrasound-assisted deep eutectic solvent extraction of echinacoside and oleuropein from Syringa pubescens Turcz," Industrial Crops and Products, vol. 151, Article ID 112442, 2020.

[19] A. Stefanucci, G. Zengin, E. J. Llorent-Martinez et al., "Viscum album L. homogenizer-assisted and ultrasound-assisted extracts as potential sources of bioactive compounds," Journal of Food Biochemistry, vol. 44, no. 9, Article ID e13377, 2020.

[20] Z. Song, Y. Hu, L. Qi et al., "An effective and recyclable deproteinization method for polysaccharide from oyster by magnetic chitosan microspheres," Carbohydrate Polymers, vol. 195, pp. 558-565, 2018.

[21] W.-M. Chan and C.-Y. Ma, "Acid modification of proteins from soymilk residue (okara)," Food Research International, vol. 32, no. 2, pp. 119-127, 1999.

[22] D. Zeng and S. Zhu, "Purification, characterization, antioxidant and anticancer activities of novel polysaccharides extracted from Bachu mushroom," International Journal of Biological Macromolecules, vol. 107, pp. 1086-1092, 2018.

[23] K. H. Musa, A. Abdullah, and A. Al-Haiqi, "Determination of DPPH free radical scavenging activity: application of artificial neural networks," Food Chemistry, vol. 194, pp. 705-711, 2016.

[24] R. Leung, C. Venus, T. Zeng, and A. Tsopmo, "Structurefunction relationships of hydroxyl radical scavenging and chromium-VI reducing cysteine-tripeptides derived from rye secalin," Food Chemistry, vol. 254, pp. 165-169, 2018.

[25] R. Re, N. Pellegrini, A. Proteggente, A. Pannala, M. Yang, and C. Rice-Evans, "Antioxidant activity applying an improved ABTS radical cation decolorization assay," Free Radical Biology and Medicine, vol. 26, no. 9-10, pp. 1231-1237, 1999.

[26] L.-N. Gao, Y.-L. Cui, Q.-S. Wang, and S.-X. Wang, "Amelioration of Danhong injection on the lipopolysaccharide-stimulated systemic acute inflammatory reaction via multi-target strategy," Journal of Ethnopharmacology, vol. 149, no. 3, pp. 772-782, 2013.

[27] M. Zhang, L. Sun, W. Zhao et al., "Cholesteryl-modification of a glucomannan from Bletilla striata and its hydrogel properties," Molecules, vol. 19, no. 7, pp. 9089-9100, 2014.

[28] B. K. Tiwari, "Ultrasound: a clean, green extraction technology," TrAC Trends in Analytical Chemistry, vol. 71, pp. 100-109, 2015.

[29] W. Chen, W.-P. Wang, H.-S. Zhang, and Q. Huang, "Optimization of ultrasonic-assisted extraction of water-soluble polysaccharides from Boletus edulis mycelia using response surface methodology," Carbohydrate Polymers, vol. 87, no. 1, pp. 614-619, 2012.

[30] M. Hadidi, A. Ibarz, and J. Pagan, "Optimisation and kinetic study of the ultrasonic-assisted extraction of total saponins from alfalfa (Medicago sativa) and its bioaccessibility using the response surface methodology," Food Chemistry, vol. 309, Article ID 125786, 2019.

[31] A. Raza, F. Li, X. Xu, and J. Tang, "Optimization of ultrasonicassisted extraction of antioxidant polysaccharides from the stem of Trapa quadrispinosa using response surface methodology," International Journal of Biological Macromolecules, vol. 94, pp. 335-344, 2017.

[32] S. Shen, D. Chen, X. Li et al., "Optimization of extraction process and antioxidant activity of polysaccharides from leaves of Paris polyphylla," Carbohydrate Polymers, vol. 104, pp. 80-86, 2014.
[33] Z.-F. Zhang, G.-Y. Lv, X. Jiang, J.-H. Cheng, and L.-f. Fan, "Extraction optimization and biological properties of a polysaccharide isolated from Gleoestereum incarnatum," Carbohydrate Polymers, vol. 117, pp. 185-191, 2015.

[34] L. Wang, B. Zhang, J. Xiao, Q. Huang, C. Li, and X. Fu, "Physicochemical, functional, and biological properties of water-soluble polysaccharides from Rosa roxburghii Tratt fruit," Food Chemistry, vol. 249, pp. 127-135, 2018.

[35] X.-H. Yu, Y. Liu, X.-L. Wu, L.-Z. Liu, W. Fu, and D.-D. Song, "Isolation, purification, characterization and immunostimulatory activity of polysaccharides derived from American ginseng," Carbohydrate Polymers, vol. 156, pp. 9-18, 2017.

[36] J.-H. Xie, Z.-J. Wang, M.-Y. Shen et al., "Sulfated modification, characterization and antioxidant activities of polysaccharide from Cyclocarya paliurus," Food Hydrocolloids, vol. 53, pp. 7-15, 2016.

[37] K. M. Schaich, X. Tian, and J. Xie, "Reprint of "Hurdles and pitfalls in measuring antioxidant efficacy: a critical evaluation of ABTS, DPPH, and ORAC assays,"' Journal of Functional Foods, vol. 18, pp. 782-796, 2015.

[38] C. J. Kearney, S. P. Cullen, G. A. Tynan et al., "Necroptosis suppresses inflammation via termination of TNF- or LPSinduced cytokine and chemokine production," Cell Death \& Differentiation, vol. 22, no. 8, pp. 1313-1327, 2015. 